\title{
Life in a lanyard: developing an ethics of embedded research methods in children's social care
}

Dr Jenny Lloyd, Senior Research Fellow, University of Bedfordshire

Jenny.lloyd@beds.ac.uk

Purpose: To consider the opportunities for embedded methodologies for research into children's social care and the ethics of this method.

Design: The study draws upon embedded research from a two year study into developing children's social work approaches to extra-familial risk. Findings draw upon personal reflections from field notes, case reviews, practice observations and reflections.

Findings: Two findings are presented. Firstly, that Embedded Research provides numerous opportunities to develop child protection systems and practice. Secondly, a number of ethical questions and challenges of the methodology are presented.

Limitations: the article draws upon personal reflections from one study and is not intended to be representative of all approaches to embedded research methods.

Practical implications: Two practical recommendations are presented. Firstly I outline a number of recommendations to university researchers and host organisations on the facilitative attributes for embedded researchers. Secondly, questions are raised to support university ethics boards to assist ethical frameworks for embedded research.

Originality: the article contributes original empirical data to the limited literature on embedded research in children's services.

Keywords: Children's social care; Contextual Safeguarding; Embedded research; Ethics; Ethnography; Extra-familial harm

Increasingly social work practice is required to be informed by evidence-based research on 'what works' (BASW 2019). Simultaneously, academics are required to demonstrate the impact and significance of their work (REF 2021). Yet the eagerness of commissioners to 
fund new and original programmes of work can leave practitioners feeling done to, not done with (Rehn 2013). Furthermore academics often face a number of number of challenges when trying to inform practice - from time-lag of research publication and uptake, access to services and simply being viewed as just another thing for already busy practitioners (Hughes 2016). Embedded research (ER) is one research method that provides opportunities to consider these challenges in context by aiming to develop stronger relationships between practice and research.

In this article I reflect on the process of becoming an embedded researcher, the challenges of this approach and the opportunities of this methodology for both research and practice in social care. I argue that ER methods provide extensive opportunities for collaborative and relevant research practice that are essential to developing research-informed practice in children's services. However, while ER provides many opportunities for collaborative working, the ethics and practicalities of doing this type of research are not extensively versed. Beyond collaborative $\mathrm{PhD}$ scholarships there are few practical guides that support researchers to consider and plan for a fieldwork method that relies heavily on personality traits and emotional labour (the management of human emotions in social interactions (Fineman 2000)). By reflecting on the literature on ER and my own experience in the field I invite readers to consider the ethical implications of this method and the need for more thoroughly developed ethical framework for ER by presenting a range of 'facilitative attributes for ER' and ethical considerations.

\section{Embedded Research}

In relation to education research McGinity and Salokangas $(2014,3)$ define embedded researchers as:

individuals or teams who are either university- based or employed undertaking explicit research roles within host schools or other educational organizations, legitimated by staff 
status or membership with the purpose of identifying and implementing a collaborative research agenda. ER describes a mutually beneficial relationship between academics and their host organizations whether they are public, private or third sector.

By becoming "some kind of member of the team" researchers spend time within organisations (Reiter-Theil 2004, 23), working towards a shared research project whereby data is captured for the purpose of informing frontline practice directly. Following from Cheetham et al. (2018) ER varies from ethnographic research in that rather than studying the context, researchers engage with those in that context to co-produce, implement and evaluate context-specific knowledge. While literature that explores this methodological approach is sparse, findings across the available research paint a similar narrative; it is collaborative, flexible, grounded in practice and research and ultimately - messy. This article draws upon a broad review of literature pertaining to "embedded research", including other search terms such as "child protection", "ethics", "ethnography" and "public health". The aim is not to provide a systemic review of literature but to ground my reflections in those of other researchers utilising this methodology. I begin by exploring the central principles of ER before considering some of the benefits and challenges of this approach.

\section{Principles}

Four key principles emerge from the research literature; that ER bridges the insider/outsider binary, is collaborative, ethnographically informed and relies on particular personal attributes. Firstly, literature on ER highlights how this approach bridges the binary between insider and outsider status, requiring a state of 'in-between-ness', offering the benefits of an outsider perspective while becoming part of the team (Lewis and Russell 2011). In doing so, researchers maintain outsider distance while their insider status contextualises findings in a way which is sympathetic to organisational systems and cultures. Common across studies is the idea that researchers take on multiple positions; the 'liquid researcher' moving fluidly 
across organisations and positions (Gunter 2014). In research within one local authority Duggan (2014) describes how he occupied multiple positions, at first a 'critical nephew' a junior role in relation to local authority managers and his own supervisors, 'critical friend' when the relationship between partners is on equal ground, and finally 'critical orphanship' in which he found himself without a project. Duggan's work highlights not only the multiple positions embedded researchers occupy, but the flexibility required to navigate often changing organisations and research climates.

Secondly, collaboration is a fundamental aspect of the ER process. For many this is contractual and practical, by working to a shared research agenda and sharing (often limited) office space. Wong (2009) outlines how collaboration in this sense requires working with organisations to increase the relevance of research to those on the ground. Working in this way draws upon practitioners' own expertise and experience to shape the research plan and methods used. Collaboration can be seen to overcome the challenges of pushing research onto practitioners or pulling data from practitioners (Marshall 2014). In this way analysis and interpretation of research findings is shared and iterative (Eyre, George, and Marshall 2015).

Thirdly, ER is a form of ethnography premised on the researcher "'being there" sufficient to experience the mundane and sacred, brash and nuanced aspects of sociocultural life and, through observations, encounters and conversations, to come to an understanding of it' (Lewis and Russell 2011, 7). However, few studies specify the types of research methods used as part of this approach, beyond 'being there'. Methods such as practice observations, fieldwork diaries, and interviews with practitioners appear common but few expressly discuss the methods applied. It appears that ER is concerned not so much with the types of methods used but the relationship between the researcher and the organisation.

Finally, almost all articles on ER highlight the importance of personal attributes of the researcher themselves. Central to this appears to be the ability of researchers to gain the trust 
of practitioners and be viewed as members of the team (Vindrola-Padros et al. 2017). While difficult to define, it appears that researcher traits such as being down to earth, non-academic, honest, collegial and someone that participates fully supports this process (Lewis and Russell 2011). The ability to communicate in a non-threatening and non-academic way is also seen to be particularly important (Hollins 2014).

\section{Opportunities and challenges}

ER offers a number of opportunities including facilitating discussions, building capacity and instigating improvement and change (see Cheetham et al 2018 for an extensive overview). In particular this method facilitates the ability to access data. As highlighted across the literature, it is clear that such access is not a guaranteed aspect of research, but through the combination of building trust and working to shared priorities, researchers in embedded positons may be able to overcome barriers to access and be able to gain data in multiple ways, including systematic and ad-hoc data. Trust appears to be a central theme across studies with an assumption that being embedded ensures that the way research data is used will be sensitive to the complexities of organisational cultures (Wong 2009).

Research outputs are also seen to be more practically applicable (Baars 2014). In setting research questions and approaches collaboratively research can be sensitive to the requirements of organisations so that outputs are relevant to the policy and organisational context (Ghaffar et al. 2017). This process can often be quicker through the iterative approach to feedback and guidance (Vindrola-Padros et al. 2017). There appear to be additional benefits such as the lasting impact of having embedded researchers within organisations: such as increasing the capacity of practitioners to engage in research to develop, refine and test practice tools (Westlake, Stabler, and McDonnell 2020), demystifying the research process and ensuring that practice is informed by current literature. 
This is not to say that ER does not come without challenges. The literature implies that the role relies significantly on personal attributes whereby researchers are required to build trust but also maintain a certain critical distance (Hackett and Rhoten 2011). So while researchers are expected to put findings in context, the requirement of building relationships can often present challenges in maintaining objectivity or disseminating findings if those findings run counter to the objectives or beliefs of the organisation (Marshall 2014, Wilkinson et al. 2021). Underlying this is the ongoing ethical considerations required of this methodology. While not unique to ER, or indeed always the case, embedded researchers are often confronted with ethical challenges when drawing data from conservations with teammates (Rowley 2014), or in cases where the methodology and aims may shift and change in response to organisational changes.

While ER involves a number of similar elements to other methodologies within children's services research, such as collaboration, co-production and action research, for the purpose of this paper I consider ER to align to the four principles outlined above. It is not however a prescriptive methodology, and is likely to be used in a variety of ways, across studies and disciplines. The challenges I raise here are not unique. For example, within practice research, emphasis is often placed on the need for partnerships between practitioners and researchers, (Julkunen 2011). However, as Austin (2020) outlines, such relationships, which are often built on trust, require careful consideration and renegotiation. Fisher (2020) highlights a number of methodological and ethical considerations within practice research in social work but emphasises the opportunities of these approaches for ensuring research questions are shaped by the equal needs of researchers, practitioners and service users ensuring outputs that are beneficial to all. Literature on action research in social work highlights the tension between ensuring outcomes are relevant to host organisations but which allow comparisons with other organisations and broader theory (Shaw 1999). Within 
child protection, the benefits - but also politics - of co-production are well-versed (Lunt, Shaw, and Fouché 2010). In outlining some of the methodological and ethical challenges of this approach it is not my intention to suggest these dilemmas are unique to (my own experiences of) ER. Instead I hope insights gleaned in this article may be of use beyond embedded methodologies.

\section{Methodology}

The findings in this article are the result of my own experiences as an embedded researcher during a two year action research study from April 2017 in one statutory children and families service in England. The project aimed to develop, test and embed a Contextual Safeguarding approach to safeguarding children from extra-familial harm and was funded by the Department for Education's innovation fund.

\section{Contextual Safeguarding}

Contextual Safeguarding, 'is an approach to understanding, and responding to, young people's experiences of significant harm beyond their families' (Firmin 2017b, 3). This approach was developed from reviews of nine cases (involving sexual exploitation, serious youth violence, teenage relationship abuse) and audits of 14 local authority responses to peeron-peer abuse in England (Firmin 2017a). Firmin's work highlights the challenge that current models of social work in England, which focus primarily on individuals and families, face when trying to respond to peer relationships or contexts where harm occurs. However, until the start of the project outlined here, Contextual Safeguarding was untested. The innovation funding was provided to support a team of researchers and practitioners to apply Contextual Safeguarding theory in practice by developing new systems and approaches within children's social care. 
While other methodologies may have been appropriate, ER was used for a number of reasons: Firstly, Contextual Safeguarding is a framework and not a model. In this sense the aim to 'test, develop and adapt the framework and underlying principles' were exploratory and required working with practitioners to create resources, systems and structures specific to that Local Authority. Secondly, Contextual Safeguarding itself is contextual, this means that we wanted to develop the process through collaboration and insights from practitioners that were specific to their experiences and organisational context as well as specific to the context of extra-familial harm in that area. Thirdly, ER provided an opportunity to overcome some practical barriers such as access to the organisation and limiting requirements on practitioners to report back. We felt that without regularly being within the site, and understanding the complex and ever-changing working environment, that it would not be possible to create an approach that was flexible and informed-by and developed-through an ongoing collaboration with practitioners.

The project team consisted of five social workers, three practitioners, one analyst, one project manager and one administrator. Alongside the practitioners the research team consisted of the principal researcher, a research assistant and myself the embedded researcher.

As embedded researcher I was employed to work 3 days a week in site with the project team. My role involved four key aims:

- Identifying, recording and feeding back examples of contextual practice in the site to the local workforce (social care and multi-agency) to ensure learning was developed, embedded and shared as the work developed

- Communicating research messages on contextual safeguarding to practitioners to advance their practice and ensure that their work was rooted in contextual theory

- Working in partnership with practitioners to develop practice-based evidence on contextual safeguarding approaches

- Identifying thematic challenges to contextual delivery to be reported into, and addressed by the programme board 
In practice this involved a range of ad-hoc ethnographic methods across the lifespan of the project. While not linear in nature these broadly focussed on capturing current approaches to extra-familial risk, working collaboratively to develop new systems and reflection with the team and practitioners across the service. These involved a range of methods including:

- Observations of meetings related to extra-familial risk

- Interviews and discussions with practitioners within and external to the team

- Observations of practice

- Leading reflective discussions with the team and practitioners

- Review of individual cases and context assessments

- Observations and engagement with new systems

- Co-creation of new systems and approaches with practitioners

- Participating in team meetings

- Reporting findings via the various governance structures

\section{Positionality}

While I occupied various positions throughout the project, and as I describe below, drew upon these throughout the research, a number of facets of my personality appeared relevant to my role as embedded researcher. I am a white, British woman with a southern English accent. Two factors that appeared most relevant to my status were my age and my professional qualifications. Firstly, while I am in my early thirties, I am often read as being much younger. Throughout my time in-site I was often misread as being a social work student undertaking an undergraduate or masters' course. Secondly, I am not trained as a social work practitioner. While I do have the title of Doctor, the combination of my perceived age, and lack of child protection experience appeared to position me within the team as non-threatening and in many respects I was able to use this positon to learn more about how the local authority 
operated.

Research process, ethics and analytical framework

In this project the research design, data collection, analysis and outputs were all completed on-site. Figure one outlines the research process for the project. This included achieving ethical approval. Approval for the project was granted by my own university and the local authority's own ethics committee. Permission for the research team to be on-site prior to ethics was granted by the Director of Children and Families. As embedded researcher I was provided with a number of non-disclosure agreements and information sharing agreements prior to this point and provided an induction and training during these initial months. A more thorough account of ethics is outlined throughout the findings and discussion. In addition to consideration of the ethics of embedded research, this research was developed through careful attention to, and experience of, conducting ethical research in the area of child abuse and child protection. 


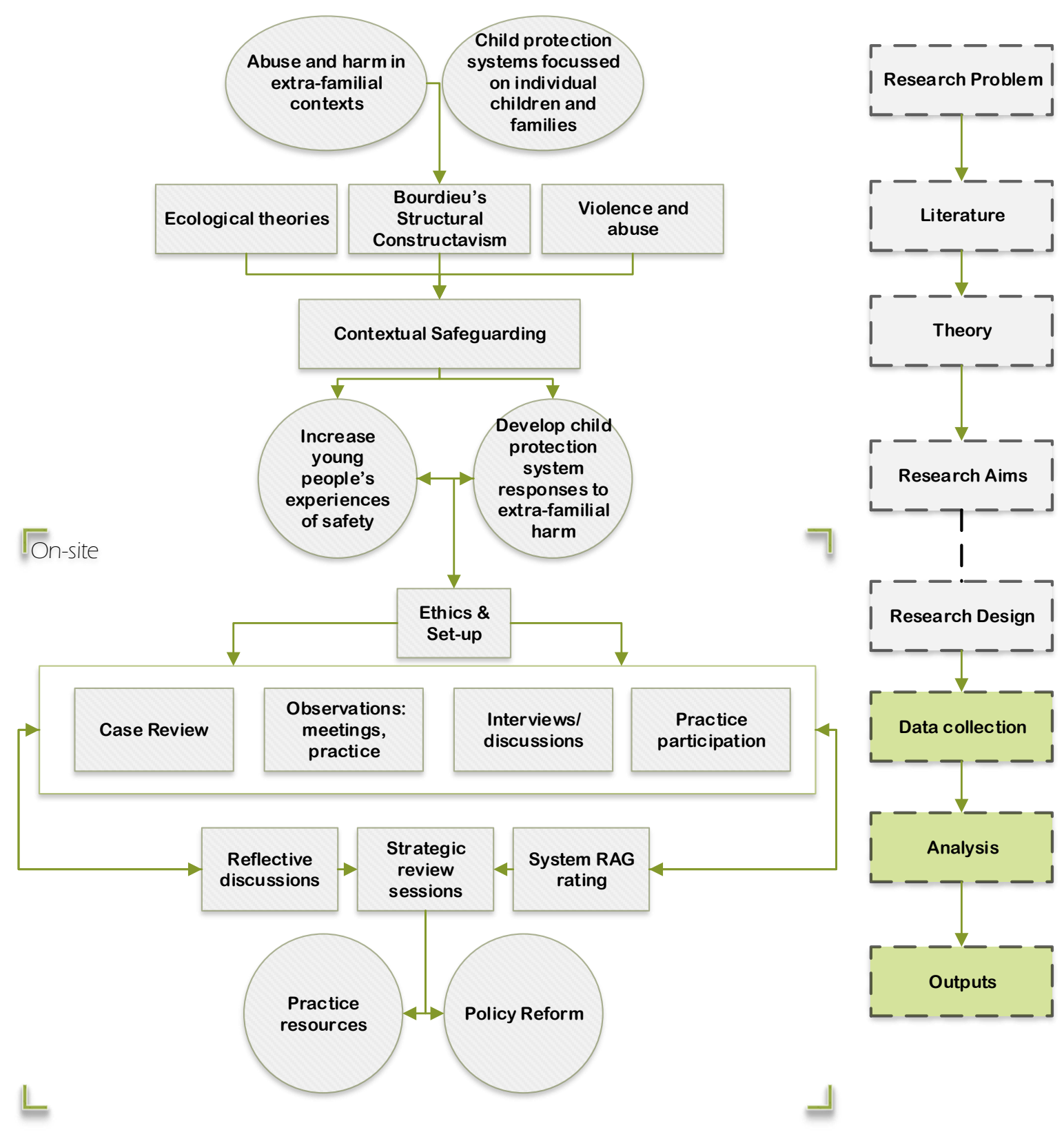

Figure one: the research process

In this article I present findings drawn from three aspects of the research process: data collection, analysis and outputs. In so doing I explore the benefits and ethical complexities of ER in children's social care. In focussing on these three areas I draw upon an analytical framework formed of the key principles identified within the literature on embedded methodologies and my two research questions. Additionally each findings section considers ethical dimensions of the research. 


\section{Managing researcher identity and capturing data}

'Being there' from day one within children's social care and sitting with the project team was essential for my ability to build the project collaboratively and form relationships with the team. Initially, my research activities predominantly focussed on understanding how. the social care system of the local authority I was in. responded to extra-familial risk. Through observations of multi-agency meetings (for example child protection conferences, youth offending meetings, the multi-agency sexual exploitation panel and team meetings) and sitting with different teams across the service I started to map out a child's journey through the system. Later on, once the full project team was in place I joined team members in their own activities such as consultations with social workers, meetings they attended across the service and with other agencies, and within weekly team meetings and reflections. While, as noted in the literature, access to data was not a challenge it did rely on team members inviting me to join them and the willingness of other staff to allow me to shadow them. Without formal structures to invite me to meetings (my workload was not determined by the information system workflow), I was often required to approach staff or set up meetings, and while most of the time staff were happy to help me, I often felt like a nuisance.

Yet when I did meet with staff, particularly those outside of my team, I was able to capture a wealth of information from other professionals about the current system and the new project. Throughout these informal conversations I occupied the position of 'critical niece' (Duggan 2014). This involved establishing myself early on as a junior researcher who 'wasn't a social worker' demonstrating to people that I was new to the area and that they could assume ignorance on my part. Positioning myself in this way helped me to establish myself as non-threatening, and being a fairly self-deprecating person, appeared to put practitioners at ease. In short, I was able to capitalise on my naivety. Yet, while this was a helpful (and at the time a true reflection of my knowledge) I would caution against too 
readily assuming the role of 'critical niece'. Firstly, adopting such a role may be disingenuous, contrived and certainly runs parallel to my feminist principles.

Linked to this was the question of how I represented myself to other practitioners and senior managers. As an embedded researcher I was acting, not only as an individual, but as part of a research team, programme and university that, during this research, was receiving increasing national strategic interest. As such my role as embedded researcher and 'knowledge broker' (Cheetham et al. 2018) was crucial to making policy and practice changes. As such, I had to develop and foster positive relationships with practitioners whom would be required to instigate changes, while also often being the 'face' of the project and organisation I was working for. In some instances this resulted in very senior members of staff (such as the Director of Children's services) asking for my reflections and thoughts on the available research and views on the service. Such incidents, while not unique to embedded research, should be carefully considered when designing, training and supporting embedded researchers.

A greater challenge was the capturing of data itself. While I kept a fieldwork diary, and used a template to record meeting observations my in-between-ness required me to capture and participate in meetings. While literature on ER speaks about the rich data that this method can gain, little is written about the ways that data is captured. While the project had a framework in place for what could be captured from an organisational and university standpoint (which was approved by my internal ethics committee) in practice it is ethically challenging to know what is being told to me as a colleague and what could be used in reports and articles. While it may be clearer what can be used in written reports, it was not always clear what was said to me as a colleague. Often I found myself navigating relationships within the project team and colleagues in the research team - unsure of what was data and what veered into office gossip. In many respects my ethical arrangements and the agreement 
of the organisation would 'allow' me to capture far more data than I personally felt may be appropriate. My in-between-ness was facilitated by access to the organisations and universities' systems, and crucially, the physical building through my security pass. But often felt I was 'living my life in a lanyard' - required to meet both the university and organisations requirements, relationships and structures of multiple institutions.

\section{Iterative analysis}

Data analysis in many instances follows when the researchers have left the field. In embedded approaches, 'being there' allows for continuous sense-checking. This iterative process involved speaking with practitioners to check if research themes and insights were accurate and to consider the impact and utility of findings through dissemination. Analysis took place alongside practitioners through formal routes such as group reflection following the testing of new methods, or informal discussions over tea. Yet insider and outside status provided a helpful opportunity to get away (often physically) from the data to speak with my university colleagues about the process and the research team. Again, the relationship between data collection and analysis was often an iterative and on-going process. By being there, and having the time and space dedicated to developing approaches, I was able to work alongside practitioners to capture and simultaneously analyse.

Moments of collaboration were often joyous and enriching. One such moment included the development of a peer assessment framework. I was developing peer assessment guidance and one of the social workers from the project team had been preparing a peer group assessment, including group work with a peer group of young people who had been referred for concerns regarding technology assisted harmful sexual behaviour. One day while we were sitting together she discussed how she had designed some questions for the group but felt she needed a framework to guide this - as is done with the child and family assessment. Working alongside each other, myself and two social workers we used the child 
and family assessment triangle to adapt a new framework for peer groups. This iterative approach involved drawing upon their substantial experience of practice and my own knowledge of contextual safeguarding theory with our combined experience of the project work so far. The results of which can be found at Anon et al (2018). Collaborating brought our knowledge from different fields together but was drawn together through the trust and relationships we had.

Finally, while literature on ER highlights the opportunities of this method to build organisational research capacity there were some unintended consequences of inviting analysis into the workplace. A large part of the project involved understanding how the current system responded to extra-familial harm. Through methods such as case review of files, observations of meetings and interviews with practitioners the research team were involved in reporting back trends and findings. While the purpose of this activity was not to shame individual practitioners but to understand what the legal and organisational threshold were for these cases, this highlighted some problematic practice. On one day I was sitting with the team when I read an extract from a case file which suggested the case be closed due to the young person nearly turning 18 years old. I mentioned this to a colleague I was sat with who, like me, found this problematic (although not uncommon) and came over to look and immediately asked who the practitioner was that had done the assessment. I realised then that my position of in-between-ness. In one way I had access like other members of the team to the shared safeguarding systems, but also was unaware of the names of individual practitioners outside my own team. This is not to say that I sat objectively outside of practice, as in this instance I was caught up in the moment of judgement - something we indulged in but my outsider position did have the benefit of reflection (and guidance by the principle investigator) that highlighted the importance of seeing this as an example of a systemic challenge. Yet in inviting this type of critique had we unwittingly invited team members to 
observe and critique others? A number of exercises after this suggested that this had become part of the process of the team, and while this offered benefits this may be challenging if it places practitioners in a position without formal avenues to relay the learning.

\section{Outputs, ownership and emotional labour}

Finally, a key aspect of my role was to generate practical research outputs from the project. Outputs were disseminated in a range of ways predominantly throughout our practice network (anon) - an online resource for practitioners interested in Contextual Safeguarding. The aim of these tools was to share learning from this project nationally and internationally by supporting practitioners outside of the local authority to develop their own responses to extra-familial harm. While ER facilitated collaborative approaches to working, the development of shared outputs was challenging. Getting the team to document their work in ways that could be shared with others was a struggle. Knowledge of practice development was often held by individuals (and left with them too) in piece-meal ways. As such getting the team to spend time explaining things to me or to review briefings I had written for them to review and edit was challenging. My position within the team and being there consistently aided this immensely as I was able to rely less on formal meetings with colleagues and could speak when they were available. At times I relied heavily on my position and relationships with the team having to 'mine' my social capital through careful emotional labour to place myself in a favourable light in which people would help me.

Ultimately, outputs were created based on information from meetings and followed up through conversations with practitioners. This, however, raised the question of authorship when data and knowledge were co-produced. While there were agreements in place at an organisational level, these had not been determined at an individual one. This evidenced some ethical challenges. Initially all documents I wrote up had the name of practitioners on them. I determined authorship rather ambiguously through consideration of who had 
contributed most to the practice development. At times this meant not putting my own name on the work I had written. While I always sent everything to the team to ask for their feedback I often didn't receive any feedback at all. This raised a dilemma. Is it better to put the names of those that I viewed as having developed the work? Or is it more ethical to put names of people who had reviewed and contributed to the written document? My decision to put the names of those that had worked on the article was very much mediated by my relationships where it would have felt unethical to claim work as my own. Yet on balance, this could raise challenges. For example, what if the guidance or outputs described problematic or unlawful practice and the authors had not properly engaged with the outputs?

A third option would be to have no-one's names but the local authority and university. In-between-ness extended beyond me to the project itself. As academics, intellectual property and authorship are often contentious and important issues. But in this service, policy documents rarely had the name of individual practitioners on them. An unintended outcome of this was that the research team may have muddied the waters by inviting this individualised approach to ownership. It seems that this may be possible. Later into the project team members started to claim products produced as part of the project as their own for use outside of the project and discussed a desire to charge for them. All the resources developed through the project are freely available.

\section{Discussion}

While there is limited literature on ER, and far less on this method from within child protection, there are a number of themes that run across the literature: the necessity of 'being there', the state of in-between-ness for researchers, the importance of collaboration and certain personal attributes. Yet even more present across the literature is the suggestion that, despite its many benefits, ER is challenging, complicated and unwieldy. From stories of institutional changes resulting in researchers being left without a project (Duggan 2014), to 
the ethical challenges of starting research in the field (Rowley 2014) - ER is messy. And while the many benefits of this method are discussed, few studies consider opportunities to maximise these through explicitly exploring the facilitative attributes of this method. Yet research that is sensitive and relevant to ever-changing practice environments is necessary for developing evidence-informed applied research which improves the lives of children, young people and, dare I say, practitioners. There is of course a host of excellent research which uses a range of methodologies to understand system responses to extra-familial harm - from participatory work (Warrington 2016) to interviews and practice observations (Lefevre, Hickle, and Luckock 2018). But, I argue, that for research to maximise the opportunities to inform practice and make change - ER methods are essential.

Within our own project Contextual Safeguarding would not have been so readily taken-up nationally without working alongside and with practitioners in the project described here. For context, since the development of Contextual Safeguarding in 2013 it has entered statutory guidance Working Together to Safeguard Children (Department for Education 2018), 50 local authorities applied to be part of a national scale-up of the programme (of which there were three places) and our practice network now has over 10,000 members. A number of factors have facilitated this. Evidence indicates that the take-up of Contextual Safeguarding correlates to concern among practitioners for the risks posed to children and young people from issues such as youth violence, criminal exploitation, child sexual exploitation and harmful sexual behaviour.

Analysis, however, suggests other factors were at work. Iterative reflections from the research team and practitioners employing Contextual Safeguarding suggest that ER itself may have acted as a 'catalyst for change' supporting communication between researchers and practitioners (Cheetham et al. 2018). Firstly, in working with social work practitioners we were able to create and develop resources that are relevant to everyday practice and attentive 
to many of the organisational challenges practitioners can encounter. For example, part of the project involved re-writing the local authorities threshold document and creating a new one for contexts in response to the challenge that many high-risk cases of extra-familial harm often 'didn't meet a threshold'. This resource is supported with a podcast and guidance with practitioners about how they use it (anon 2019). This was a complex and iterative process involving ongoing relational working across teams and at strategic and operational level to facilitate buy-in and mediate challenges. It required me to review multiple cases to provide organisation evidence alongside academic evidence and at a practical level it required myself and a practitioner to work together to make changes, format the document and continue the momentum - all which relied heavily on relationships and work facilitated by ER. Secondly, ER allowed us to engage stakeholders throughout the development of the project reducing the feeling of being 'done to'. This is essential to how we now disseminate information about the project. Often we deliver training alongside 'practice champions' - training which is undoubtedly enlivened with current examples of cases. Often this requires us to draw on the social capital we have gained in the project and ultimately the trading of favours. Realistically busy practitioners (and researchers) are more inclined to help and support colleagues whom they have developed relationships with. Finally, from a personal perspective, working alongside practitioners, being a part of shared frustration/sadness/anger of some cases I have developed my own understanding and language related to child protection. I am not a social worker, but I am empathetic to the needs and requirements of those we are trying to engage through a shared language, humour and knowledge - ER has given me access to the language and world of child protection.

The second focus of this paper is the question of ethics. While embedded methodologies are employed in a variety of fields there are few ethical frameworks that explicitly support researchers and ethics boards to develop ethically conducted embedded 
research. While the challenges and ethical dilemmas of this method are documented throughout the literature, beyond Rowley's (2014) article, few studies explicitly provide recommendations to explore the ethical dilemmas and create an ethics of embedded research. In this last section I present a number of ethical considerations for researchers seeking to employ this method, the organisations that host them and the university ethics boards which oversee this process

Drawing upon my own experiences and literature in this field table one summarises a number of facilitative attributes and considerations for researchers. Drawing upon the four key principles of embedded research, column two and three summarise key attributes which would facilitate the method. Column two outlines those for researchers and column three those of host organisations and universities.

\section{Insert table one}

Table one: Facilitative attributes for embedded research

\section{An ethics of embedded research}

Column four presents four ethical questions drawn from my own experiences and a number of recommendations for ethics boards. While these recommendations are drawn from my own experiences (and shortcomings) at my own institution it is likely that these would be relevant to ethics boards elsewhere. Following from Rowley (2014), one of the strongest deviations from some other research (and therefore ethics) processes is that fact that often, although not always, embedded researchers start in the field at the beginning of the project. The benefits of this mean that the research design, questions and methodology can be developed in collaboration with the organisation. As such, a formal ethics application is not often possible when it is unclear what the research will be. The challenges of this are 
numerous. Firstly this means that projects have often not yet received ethical approval, it is unclear what data can be captured and used prior to receiving ethical approval, or what the process should be if concerns arise. While many institutions provides mechanisms to amend and vary ethics applications, ethics processes can be lengthy. This can be a challenge if researchers are only able to research and capture evidence once the ethics process has been completed. In my own institution it would have been helpful to submit a shorter ethics notice prior to the full application. This could include: safety arrangements for the researcher, safeguarding arrangements and referral routes in the organisation and university, what data could be captured prior to the research, how this will be stored and what can be used after achieving successful ethics approval.

Secondly, it is important to be transparent about what and how data will be captured to both the university and host institution. For example, what methods will be used? Will the researcher audio record, take field notes or use documents such as minutes from meetings. And how will participants be informed what and when is being documented? It is important to clearly outline to practitioners their intentions at the start of the project. This should form part of an ongoing and reflective discussion about what they are happy for you to capture, how it will be used and how you will ensure consent. While this was required as part of my own ethics application it was not a continued part of the ongoing research process with the team. Even better would be working with the team for them to decided how and what would be recorded at the start of the project.

Thirdly, in addition to determining who owns the research and how it will be disseminated at a university and organisational level it is important to consider this at an individual and group level across researchers and practitioners. It may be helpful to consider all possible outputs - journal articles, academic presentations and practice resources, policies etc. at the start and what the approach will be to authorship, copyright, fees and availability. 
Finally, the important issue of researcher welfare. Repeated across literature is the idea that embedded researchers must demonstrate a range of positive personal attributes and use these to be sociable, collegial and helpful to organisations. But it is important to recognise that such emotional labour is often tiring and demanding. Greater practical support is required for researchers. For example, regular supervision from university colleagues and the organisation where researcher welfare is prioritised and clinical supervision is made available. This is not so much about the topic under study (in my case child abuse) but the extent to which the method requires practitioners to draw on relationships. Outlining at the start to colleagues and researchers that the method is demanding and the potential impacts that 'mining' social capital can have - ultimately acknowledging the very real impact of methods that rely on personal attributes. Finally, providing opportunities to support the development of friendships and social networks that allow the researcher to express their own thoughts and experiences - you are not just a passive observer and are likely to be affected by the research and organisation you are in even if you are not 'on the frontline'.

ER is a complex and consuming method. It requires researchers to work away from their institutions, to navigate complex organisations and have the confidence to critique the practice and work of their sponsor. While I believe that this is a valuable method for researchers at any level -greater research is required to explore how best to maximise and plan for this method. This article argues that ER is a method that is valuable and essential to research on children's services. For the purpose of this project, and the wider aims of Contextual Safeguarding, being embedded has facilitated the development of theory relevant to practice and continues to shape its on-going development ensuring practice outputs are applicable beyond the organisation. However, in order to do so I argue that we require a thoroughly developed research and ethics framework. This article supports ethics boards and 
organisations to start this conversation and opportunities to create a thorough framework for researchers in a range of fields.

\section{References}

Austin, M.J. . 2020. "Identifying the Conceptual Foundations of Practice Research." In Handbook on Practice Research, edited by L. Joubert and M. Webber. London: Routledge.

Baars, Sam. 2014. "The retreat of the state and the future of social science." Management in Education 28 (1):6-11.

BASW. 2019. "Professional Capabilities Framework." accessed 7th November 2019. https://www.basw.co.uk/professional-development/professional-capabilities-frameworkpcf\#start.

Cheetham, Mandy, A Wiseman, B Khazaeli, E Gibson, P Gray, P Van der Graaf, and R Rushmer. 2018. "Embedded research: a promising way to create evidence-informed impact in public health?" Journal of Public Health 40 (suppl_1):i64-i70.

Department for Education. 2018. Working Together to Safeguard Children. HM Government.

Duggan, James R. 2014. "Critical friendship and critical orphanship: embedded research of an English local authority initiative." Management in Education 28 (1):12-18.

Eyre, Laura, Bethan George, and Martin Marshall. 2015. "Protocol for a process-oriented qualitative evaluation of the Waltham Forest and East London Collaborative (WELC) integrated care pioneer programme using the Researcher-in-Residence model." BMJ open 5 (11):e009567.

Fineman, Stephen. 2000. Emotion in organizations: Sage.

Firmin, Carlene. 2017a. "Contextual Risk, Individualised Responses: An Assessment of Safeguarding Responses to Nine Cases of Peer-on-Peer Abuse." Child Abuse Review.

Firmin, Carlene. 2017b. Contextual Safeguarding: An overview of the operational, strategic and conceptual framework.

Fisher, M. 2020. "From research question to practice research methodology." In Handbook on Practice Research, edited by L. Joubert and M. Webber. London: Routledge.

Ghaffar, Abdul, Etienne V Langlois, Kumanan Rasanathan, Stefan Peterson, Lola Adedokun, and Nhan T Tran. 2017. "Strengthening health systems through embedded research." Bulletin of the World Health Organization 95 (2):87.

Gunter, Helen. 2014. "In and out, and roundabouts." Management in Education 28 (1):25-26.

Hackett, Edward J, and Diana R Rhoten. 2011. "Engaged, embedded, enjoined: Science and technology studies in The National Science Foundation." Science and engineering ethics 17 (4):823-838.

Hollins, Kevin. 2014. "No school is an island." Management in Education 28 (1):27-28.

Hughes, Mark. 2016. "Research Engagement and Impact: Challenges and Opportunities." Australian Social Work 69 (4):385-387. doi: 10.1080/0312407X.2016.1219976.

Julkunen, I. . 2011. "Knowledge-Production Processes in Practice Research - Outcomes and Critical Elements." Social Work \& Society 9 (1):60-75.

Lefevre, Michelle, Kristine Hickle, and Barry Luckock. 2018. "'Both/And' Not 'Either/Or': Reconciling Rights to Protection and Participation in Working with Child Sexual Exploitation." The British Journal of Social Work 49 (7):1837-1855. doi: 10.1093/bjsw/bcy106.

Lewis, Sue J, and Andrew J Russell. 2011. "Being embedded: A way forward for ethnographic research." Ethnography 12 (3):398-416. 
Lunt, Neil, lan Shaw, and Christa Fouché. 2010. "Practitioner research: collaboration and knowledge production." Public Money \& Management 30 (4):235-242. doi: 10.1080/09540962.2010.492185.

Marshall, Martin. 2014. "Researchers-in-Residence: a solution to the challenge of evidence-informed improvement?" Primary health care research \& development 15 (4):337-338.

McGinity, Ruth, and Maija Salokangas. 2014. "Introduction:'embedded research'as an approach into academia for emerging researchers." Management in Education 28 (1):3-5.

REF. 2021. Guide for research users.

Rehn, A. 2013. "Are you creating innovation fatigue? ." accessed 7th November 2019. http://www.astd.org/Publications/Blogs/Workforce-Development-Blog/2013/01/

Reiter-Theil, Stella. 2004. "Does empirical research make bioethics more relevant?"The embedded researcher" as a methodological approach." Medicine, Health Care and Philosophy 7 (1):1729.

Rowley, Harriet. 2014. "Going beyond procedure: engaging with the ethical complexities of being an embedded researcher." Management in Education 28 (1):19-24.

Shaw, I. . 1999. "Evidence for practice." In Evaluation and Social Work Practice, edited by I. Shaw and J. Lishman, 14-40. London: Sage.

Vindrola-Padros, Cecilia, Tom Pape, Martin Utley, and Naomi J Fulop. 2017. "The role of embedded research in quality improvement: a narrative review." BMJ Qual Saf 26 (1):70-80.

Warrington, C. . 2016. Young person centred approaches in child sexual exploitation - promoting participation and building self-efficacy: Frontline tool. . Dartington: Research in Practice.

Westlake, David., Lorna. Stabler, and John. McDonnell. 2020. "Direct observation in practice: codeveloping an evidence-informed practice tool to assess social work communication." Journal of Children's Services 15 (3):123-140. doi: 10.1108/JCS-08-2019-0043.

Wilkinson, K., J. Day, J. Thompson-Coon, V. Goodwin, K. Liabo, G. Coxon, G. Cox, C. Marriott, and I. A. Lang. 2021. "A realist evaluation of a collaborative model to support research co-production in long-term care settings in England: the ExCHANGE protocol." Research Involvement and Engagement 7 (1):18. doi: 10.1186/s40900-021-00257-2.

Wong, Sandie. 2009. "Tales from the frontline: the experiences of early childhood practitioners working with an 'embedded'research team." Evaluation and program planning 32 (2):99108.

Article accepted:28 June 2021

DOI: 10.1108/JCS-12-2019-0047

Journal of Children's Services

Emerald allows authors to deposit their AAM under the Creative Commons Attribution Non-commercial International Licence 4.0 (CC BY-NC 4.0). To do this, the deposit must clearly state that the AAM is deposited under this licence and that any reuse is allowed in accordance with the terms outlined by the licence. To reuse the AAM for commercial purposes, permission should be sought by contacting permissions@emeraldinsight.com. 
For the sake of clarity, commercial usage would be considered as, but not limited to:

o Copying or downloading AAMs for further distribution for a fee;

o Any use of the AAM in conjunction with advertising;

o Any use of the AAM by for promotional purposes by for-profit organisations;

o Any use that would confer monetary reward, commercial gain or commercial exploitation.

Emerald appreciates that some authors may not wish to use the CC BY-NC licence; in this case, you should deposit the AAM and include the copyright line of the published article. Should you have any questions about our licensing policies, please contact permissions@emeraldinsight.com. 